\title{
Lectores y libros: acerca de la lectura en la Antigüedad Latina
}

\author{
Gabriela MONTI \\ Universidad Nacional del Sur - Argentina \\ montigabriela@live.com.ar
}

Recibido: 28 de agosto de 2013

Aceptado: 17 de febrero de 2014

\section{RESUMEN}

En el presente trabajo nos proponemos analizar qué competencias debía desarrollar el lector de libros entre los siglos I a.C. y I d.C., en el marco de la Antigüedad Latina, y cómo llegaban esos libros a las manos de ese lector. Las destrezas puestas en juego en el acto de leer no solo debían ser de orden intelectual sino también físico, pues era necesario que quien leyera un rollo hubiera desarrollado una capacidad técnica tal que la manipulación del instrumento no le entorpeciera su lectura. La respuesta acerca de cómo accedían los lectores a los libros está directamente relacionada con el círculo social al que pertenecían. Con el objetivo de arrojar luz sobre estas dos cuestiones abordaremos las prácticas concretas de lectura que aparecen representadas en distintos autores del período mencionado.

Palabras clave: Antigüedad Latina. Lectores. Libros.

Monti, G., «Lectores y libros: acerca de la lectura en la Antigüedad Latina», Cuad. Fil. Clás. Estud. Lat. 34.1 (2014) 7-17.

\section{Readers and books: about reading in Latin Antiquity}

\begin{abstract}
In this work we aim to analyse which competencies the reader of books had to develop between the I B.C. and I A.C centuries, in the realm of Latin Antiquity, and how those books reached that reader. The skills that were brought into play in the act of reading had to be both of intellectual and physical nature, since it was necessary for anyone who read a roll to have developed such a technical ability at the handling of the instrument that it would not hamper the reading of itself. The answer to how the readers had access to the books is directly connected with the social circle they belonged to. In order to shed light on these two topics we will approach the actual reading practices that are depicted by different authors of the aforementioned period.
\end{abstract}

Keywords: Latin Antiquity. Readers. Books.

Monti, G., «Readers and books: about reading in Latin Antiquity», Cuad. Fil. Clás. Estud. Lat. 34.1 (2014) 7-17.

Sumario: 1. Hoy: Libros para todos y todas. 2. En la Antigüedad Latina: lectores, rollos y algo más. 3. El circuito de producción: del escritor al lector. 4. Referencias bibliográficas. 


\section{HOY: LIBROS PARA TODOS Y TODAS}

Esta fórmula, recurrente en nuestro tiempo, podría haber sido imaginada como un horizonte posible para la idea de expansión progresiva de la Modernidad en relación con el acceso a la lectura. Digámoslo de otro modo: la idea de que la lectura sea una práctica universalizada tiene como base un proyecto ideológico que encuentra su recorrido a partir de la Ilustración, y que se sostiene en una práctica de orden prioritariamente intelectual y una tecnología de publicación de costo accesible y volúmenes fácilmente manipulables. En el prólogo a la edición de los textos críticos de Ruskin, Marcel Proust (2003, pp.9-10) evoca una escena de lectura en estos términos:

No hay quizás días de nuestra infancia que no hayamos vivido tan plenamente como aquellos que pasamos con uno de nuestros libros preferidos. Todo aquello que parecía entretener a los demás nosotros lo apartábamos como un obstáculo vulgar ante un placer divino: el juego que un amigo venía a proponernos justo en el pasaje más interesante, la abeja o el rayo de sol molestos que nos forzaban a levantar los ojos por sobre la página o a cambiar de lugar, las provisiones para la merienda que nos habían hecho llevar y que dejábamos a nuestro costado, sobre el banco, sin tocarlas, mientras que por encima de nuestra cabeza el sol perdía fuerza en el cielo azul, la cena que nos aguardaba y de la que sólo pensábamos en salir para terminar, enseguida después, el capítulo interrumpido. La lectura nos hacía sentir la incomodidad de todo aquello, pero esta gimnasia intelectual grababa en nosotros un recuerdo tan dulce (mucho más preciado, a nuestro juicio actual, que aquello que leíamos con tanto amor) que, si se nos ocurre todavía hojear los libros de antaño, es simplemente como revisar esos únicos almanaques conservados de días extinguidos, con la esperanza de ver reflejados en sus páginas las casas y los estanques que ya no existen.

El joven, ni demasiado fuerte ni resistente, se sustrae al ritmo y las exigencias del mundo con su libro y se abandona a una práctica solitaria y descansada de la que solo con fastidio pueden arrancarlo para devolverlo al orden cotidiano. El acceso material a los libros y la alfabetización como práctica intelectual extendida nos permiten imaginar esta escena multiplicada en diferentes contextos modernos.

En el mundo latino, estas dos condiciones eran bien diferentes. La lectura, la posibilidad y su práctica, no estaban extendidas. Frente al interrogante acerca de las posibilidades de la lectura en el marco histórico que nos ocupa (siglo I a.C. y I. d.C.) es necesario realizar una cartografía que dé cuenta de quiénes podían leer y qué podían leer.

\section{EN LA ANTIGÜEDAD LATINA: LECTORES, ROLLOS Y ALGO MÁS}

Quintiliano, en sus Institutiones Oratoriae 1.3.1-2, en relación a las destrezas que debía adquirir el niño-lector de poesía, señalaba:

superest lectio: in qua puer ut sciat ubi suspendere spiritum debeat, quo loco uersum distinguere, ubi cludatur sensus, unde incipiat, quando attollenda vel summittenda 
sit uox, quid quoque flexu, quid lentius celerius concitatius lenius dicendum, demonstrari nisi in opere ipso non potest. II. Vnum est igitur quod in hac parte praecipiam, ut omnia ista facere possit: intellegat. Sit autem in primis lectio uirilis et cum sanctitate quadam grauis, et non quidem prosae similis $(. . .)^{1}$.

Aprender a leer suponía no solo un entrenamiento intelectual sino también una preparación física. Lejos de aquella escena moderna del joven lector laxo y sustraído del mundo, el niño debía desarrollar habilidades relacionadas no solo con el oído y la vista, sino también con la postura, la voz, las manos, la respiración. Todo el cuerpo del lector requería de un entrenamiento y de una preparación adecuada que potenciara sus destrezas al momento de leer. En este sentido, la figura de niño-lector que construye Quintiliano no es la imagen extendida de todos los niños del imperio romano, sino la configuración de quien sería 'un futuro orador'. El entrenamiento al que alude es aquel que debe ejercitar un lector de rollos, es decir, de libros ${ }^{2}$. Sin embargo, este no era el único soporte de escritura ni los libros eran el único material posible de ser leído. Las características propias de los textos (extensos o breves, anotaciones caseras, de índole comercial o jurídica, grafitis, epitafios) y su soporte (el rollo de papiro o pequeñas hojas construidas con el mismo material, las tablillas de madera y de arcilla, las vasijas, las paredes, las lápidas) generaban distintos tipos de lectores. No todos leían de la misma manera ni todos podían leer todo, ya que existían distintas competencias que se desarrollaban según el nivel de aprendizaje que cada individuo había logrado alcanzar. Tal como señala F. Kenyon (1932, p.78) al hablar puntualmente del nacimiento de la literatura latina, debemos suponer que el hábito de la lectura de un rollo no era una práctica extendida, pues el nivel de educación que suponía y en el que se ejercitaba este tipo de práctica estaba confinado al nivel social más alto. La educación de un niño podía llevarse a cabo a través del sistema formal (en la escuela) o informal (en la casa). En relación con el primero, mientras que al nivel inicial el niño ingresaba a los siete años y permanecía allí hasta los once o doce, el siguiente se extendía hasta la edad en la que los niños recibían la toga viril (a los quince años generalmente) para pasar a los estudios superiores, que duraban hasta los veinte años aproximadamente. En los primeros años se aprendía básicamente a leer, a escribir y a realizar cálculos. Al nivel escolar siguiente no llegaba la misma cantidad de niños y niñas que habían podido alcanzar el primero: «la sociedad romana fue siempre una sociedad aristocrática, y los estudios superiores formaban parte de los privilegios de la élite» (Marrou 1955, p.336). El nivel escolar intermedio estaba destinado al estudio gramatical de la lengua y a la explicación de los poetas. Durante

\footnotetext{
1 Traducción: «Nos queda hablar de la lectura. Solo a través de la práctica misma puede enseñarse al niño dónde debe contener la respiración, en qué lugar separar el verso, dónde concluye una idea, dónde comienza, cuándo hay que subir o bajar la voz, qué hay que decir con cierta inflexión o con mayor lentitud o más rápidamente, o con mayor vehemencia o más suavemente. Para que el niño pueda hacer todo esto recomiendo que entienda lo que está leyendo. Que su modo de leer sea viril e intenso, y que no sea similar a la lectura de la prosa».

${ }^{2}$ Hasta los siglos II y III d.C. los textos se materializaban generalmente a través de los rollos de papiro (Cavallo 2011, p.107).
} 
estos años de estudio se atendían las dificultades propias de la lectura (Marrou 1955, pp.325-342). El último nivel de estudios estaba destinado al arte de la oratoria. Sin embargo, como señalamos anteriormente, la escuela no era el único camino para aprender a leer y a escribir. Para los más privilegiados existía la figura del tutor privado que educaba a los niños de la casa. Estos tutores eran generalmente esclavos que habían sido instruidos en la lectura y en la escritura por sus dueños en la medida en que estas competencias fueran necesarias para el trabajo (Harris 1983, p.95). Más allá de los distintos tipos de lectores según el grado de escolarización formal o informal que adquirieran, el lector de libros literarios poseía un 'alto grado de dominio técnico y cognoscitivo' (Cavallo 2011, p.107).

Leer un uolumen no era una tarea ni cómoda ni sencilla. El lector, que leía de pie o sentado, en voz alta, solo o frente a un auditorio, tomaba el rollo con la mano derecha, desde el espacio superior en blanco, y lo iba desenrollando con la izquierda de modo tal que, una vez finalizada la lectura, todo el rollo quedaba envuelto en esta última (Cavallo 2011, p.107) ${ }^{3}$. El largo del rollo podía variar y solía ajustarse a la conveniencia o costumbre. El texto se organizaba en columnas y se calcula que, en su forma más extendida, cada una de las dos columnas tenía entre 25 y 45 líneas y cada línea entre 18 y 25 letras. También había papiros que constaban de tres columnas con una cantidad aproximadamente de entre 75 y 135 líneas cada una. Mientras que un modesto rollo podía tener 3 metros de largo, el más extenso llegaba a los 15 metros 4 . Esto hacía que la superficie escribible variara entre los $0,65 \mathrm{~m}^{2}$ y los $5,3 \mathrm{~m}^{2}$ (Sickle 1980, p.6). El largo del rollo determinaba su peso, que incluso podía resultar excesivo para el lector, tal como lo testimonia Plinio el Joven al contar la anécdota de Virgino Rufo, quien a los ochenta y tres años había trastabillado a causa del tamaño del libro que tenía en sus manos: Nam cum uocem praepararet acturus in consulatu principi gratias, liber quem forte acceperat grandiorem, et seni et stanti ipso pondere elapsus est (Ep.2.1.5) .

Mientras que la voz transformaba en sonido lo que el lector repasaba con la vista, ese sonido era escuchado por él mismo y, en el caso de lecturas compartidas, por su auditorio. No obstante, antes de la reproducción sonora el ojo debía llevar a cabo distintas acciones. En relación a la escritura, hasta el siglo I d.C. las palabras estaban separadas por puntos (interpuncta). A partir del siglo II se impuso la scripto continua, es decir, la escritura sin la mediación ni de espacios ni de signos entre palabras. Esto hacía que el lector no solo tuviera que sortear las dificultades del tipo de letra empleado por el copista sino también reconocer el inicio y el final de cada palabra, establecer las pausas, leer expresivamente, adecuar la entonación (Cavallo 2011, pp.110-111). Se supone que en el caso de las lecturas frente a un auditorio el

\footnotetext{
${ }^{3}$ El título del texto no constaba en el inicio del rollo sino en el final (Kenyon 1932, p.58).

${ }^{4}$ El tamaño promedio de un texto literario griego era entre 6 y 9 metros (Sickle 1980,p.7). También podía suceder que un texto necesitara de varios volumina tal como lo refiere Ovidio acerca de su Metamorfosis en Tr.3.18-19 (Kenney 1989, p.32).

5 Traducción.: «Cuando se preparaba para agradecer al príncipe por el consulado, el enorme libro que casualmente había agarrado, siendo ya anciano y estando de pie, se le cayó a causa del peso».
} 
lector conocía el texto de modo tal de asegurarse poder leerlo. Leer era producir en la medida en que la página de papiro era absolutamente neutral, ya fuera por la ausencia de signos de puntuación que marcaran las pausas lógicas, sintácticas o de respiración, por la ausencia de espacios en blanco y de letras mayúsculas, por la scripto continua. Esto hacía que el lector debiera realizar un gran esfuerzo ocular. El ojo reconoce distintas longitudes dentro del campo visual: en lo que se denomina 'visión aguda' el ojo distingue detalladamente el contorno de cada letra; en un campo más amplio, llamado 'visión parafovea', percibe 15 caracteres a la derecha a partir del punto de fijación de la vista y el área de 'visión periférica' permite el reconocimiento de características muy gruesas del texto. Las últimas dos 'visiones' son las que le permiten al lector anticiparse con la vista a aquello que está pronunciando (Pérez Cortés 2010, pp.121-122). La ausencia de los signos de ayuda reconocibles para estas dos últimas áreas del ojo hacía que la tarea del lector resultara más compleja, pues mientras reproducía en sonidos lo que ya había repasado con la vista y retenido brevemente en su memoria, debía mirar las palabras que seguían en el texto. A propósito de ello, Quintiliano señala:

Nam prospicere in dextrum, quod omnes praecipiunt, et prouidere non rationis modo sed usus quoque est, quoniam sequentia intuenti priora dicenda sunt, et, quod difficillimum est, diuidenda intentio animi, ut aliud uoce aliud oculis agatur. Illud non paenitebit curasse, cum scribere nomina puer, quemadmodum moris est, coeperit, ne hanc operam in uocabulis uulgaribus et forte occurrentibus perdat (Inst.1.1.34) ${ }^{6}$.

El lector era un intérprete cuya voz era casi el único medio del que disponía para construir el sentido del texto. A través de la entonación, de la modulación, de la cadencia, de la actitud adoptada en ese momento, debía dotar al texto de un significado que transmitía a través de la voz. Este esfuerzo por adaptar la voz a un texto y que el mismo se transformara en un sonido 'exitoso' era percibido por el auditorio. Así lo advierte Plinio el Joven en Ep.5.17.3-5, en la carta dirigida a Vestricio Spurinna:

Scio quanto opere bonis artibus faueas, quantum gaudium capias, si nobiles iunenes dignum aliquid maioribus suis faciant. Quo festinantius nuntio tibi fuisse me hodie in auditorio Calpurni Pisonis. 2 Recitabat $\kappa \alpha \tau \alpha \sigma \tau \varepsilon \rho 1 \sigma \mu \tilde{\nu}$ eruditam sane luculentamque materiam. Scripta elegis erat fluentibus et teneris et enodibus, sublimibus etiam, ut poposcit locus. Apte enim et uarie nunc attollebatur, nunc residebat; excelsa depressis, exilia plenis, seueris iucunda mutabat, omnia ingenio pari. 3 Commendabat haec uoce suauissima, nocem uerecundia: multum sanguinis, multum sollicitudinis in ore, magna ornamenta recitantis. Etenim nescio quo pacto magis in studiis homines timor quam fiducia decet. 4 Ne plura - quamquam libet plura, quo sunt pulchriora de iunene, rariora de nobili -, recitatione finita multum ac diu exosculatus adulescentem, qui est

\footnotetext{
${ }^{6}$ Traducción: «Pues mirar hacia la derecha, como todos recomiendan, y observar anticipadamente lo que sigue, no tiene que ver solo con el modo de entender sino también con el ejercicio, porque mientras se está mirando con lo que sigue se está pronunciando lo que está antes, y, lo que es más difícil, se debe dividir la atención del pensamiento en dos, para que una cosa haga la voz y otra, los ojos».
} 
acerrimus stimulus monendi, laudibus incitaui, pergeret qua coepisset, lumenque quod sibi maiores sui praetulissent, posteris ipse praeferret ${ }^{7}$.

Plinio analiza una situación particular de lectura y le imprime un giro a la consciencia del dominio del cuerpo en situación de lectura. Quintiliano hablaba de la formación de oradores, y Plinio muestra cómo un joven, formado en las tradiciones de las familias en las que la voz de mando podría volverse un tono monocorde, es capaz de acompañar con su cuerpo la búsqueda de la tensión que el texto requiere para su lectura. Entonces, a la variación tonal de las inflexiones de la voz le agrega un histrionismo que no puede ser sino aprendido. El joven lector no solamente había sido capaz de sustraerse a su modo ordinario de comportamiento y había sabido adaptar su voz y su tono a la materia leída sino que también había elegido la timidez como postura para desarrollar su lectura. Plinio celebra la sabiduría de quien puede comprender el sentido del texto y pasarlo por el cuerpo y por la voz para volverlo inteligible en toda su dimensión.

\section{EL CIRCUITO DE PRODUCCIÓN: DEL ESCRITOR AL LECTOR}

G. Cavallo y Roger Chartier, en la Introducción a Historia de la lectura en el mundo intelectual (2011, p.26), señalan que «la lectura no es solamente una operación individual abstracta: es una puesta a prueba del cuerpo, la inscripción en un espacio, la relación consigo mismo o con los demás». En los apartados anteriores nos ocupamos de las dos primeras cuestiones que mencionan Cavallo y Chartier para centrarnos ahora en la última: en las relaciones interpersonales como determinantes del proceso de edición y publicación de los libros. En la carta 5.12, dirigida a Terencio Scauro, Plinio el Joven menciona que antes de 'publicar' un discurso breve piensa convocar a un pequeño grupo de amigos para que, a partir de la lectura de dicho texto en voz alta, le acerquen su cuidadosa crítica:

Recitaturus oratiunculam quam publicare cogito, aduocaui aliquos ut uererer, paucos ut uerum audirem. Nam mihi duplex ratio recitandi, una ut sollicitudine intendar, altera ut admonear, si quid forte me ut meum fallit. 2 Tuli quod petebam: inueni qui

\footnotetext{
7 Traducción: «Conozco tu culto por las bellas letras y el placer que te da cuando ves que jóvenes de buenas familias se muestran en algo dignos de sus ancestros. También te quiero contar lo que sucedió en la sala de lectura de Calpurnio Pisón. Leía los katasterismoí, un tema ciertamente sabio y bello. El poema estaba escrito en versos elegíacos fluidos, graciosos y sencillos, y al mismo tiempo, majestuosos, tal como lo requiere la materia. Sabiendo cómo leer, él aumentaba y disminuía el tono: lo sublime le dejaba lugar a lo simple, lo ligero a lo grave, lo severo a lo juguetón, y todo lo hacía bien. Estas cualidades se volvían más valiosas porque su voz era muy agradable y su voz se admiraba más aún por su modestia: sobre su rostro, un vivo rubor, una gran timidez, que se añadía al encanto de la lectura; no sé por qué razón se tiene por más sentadora la timidez que la seguridad en los hombres de letras. Para no abundar-aunque debo agregar que estas cualidades, bellas en un joven, son raras en un noble- cuando terminó su lectura, le di al joven largos y repetidos besos, y como ningún consejo es más estimulante, lo animé con mis elogios: que siguiera hasta el final de su vida sosteniendo la antorcha con la que sus ancestros guiaban a sus descendientes».
} 
mihi copiam consilii sui facerent, ipse praeterea quaedam emendanda adnotaui. Emendaui librum, quem misi tibi. 3 Materiam ex titulo cognosces, cetera liber explicabit, quem iam nunc oportet ita consuescere, ut sine praefatione intellegatur. 4 Tu uelim quid de uniuerso, quid de partibus sentias, scribas mihi. Ero enim uel cautior in continendo uel constantior in edendo, si huc uel illuc auctoritas tua accesserit (Ep.5.12.1-4) ${ }^{8}$.

Plinio recrea una escena de lectura frecuente en la Antigüedad Latina: la de la lectura en voz alta frente a un auditorio conocido. Esta forma de circulación del texto en forma oral podía estar antecedida o seguida por el envío del rollo a amigos cercanos del autor con el objetivo de que le acercaran su visión respecto del escrito. Esta decisión suponía que el rollo circularía solo entre las personas elegidas por el autor para su lectura, tal como es posible advertir en la carta de Cicerón a su amigo Ático: De Bruto scribam ad te omnia. librum tibi celeriter mittam de gloria. excudam aliquid (Hraklei/deion quod lateat in thesauris tuis (Cic. Att.15.27.2)9.

La consulta que se desprendía de la lectura en voz alta frente a un grupo seleccionado le aseguraba al escritor que el rollo no circularía hasta que él mismo hubiera escuchado las posibles críticas y lo hubiera pulido. La oralidad como vehículo para la transmisión entre un grupo selecto fabricaba las condiciones para el surgimiento de una discusión directa en torno a las posibles correcciones y funcionaba como propaganda del trabajo. Al mismo tiempo, contribuía a reforzar la idea de 'propiedad' entre el texto y la persona que lo había escrito, imagen que se desdibujaría conforme ese texto se alejara en espacio y tiempo de la mirada de su autor (Habinek 1998, p.103). Más allá de las distintas formas de consulta, vía oral o vía escrita, tanto la recitatio como el envío del rollo a determinadas personas le permitían al autor obtener una crítica simpatética en razón de la esfera cultural común que lo acercaba a su selecto auditorio. En relación al texto escrito, Raymond Starr señala que el texto, copiado en la casa del autor por sus esclavos, circulaba en 'círculos concéntricos' determinados por las relaciones de amistad y de estatus social, propiciando la permanencia de la obra bajo la órbita de poder del escritor. Mientras que numerosas son las fuentes que

\footnotetext{
8 Traducción: «Como iba a ofrecer una reunión en la que leería un texto breve que pienso publicar, llamé a algunos pocos amigos cuya presencia no me intimidara para que pudieran escuchar cuidadosamente lo que iba a leerles. Dos motivos me movilizaban a hacer esto. El primero, yo sería interpelado amablemente. El segundo, sería advertido ante una eventual equivocación. Recibí lo que deseaba. Encontré a quienes me dieron su consejo respecto de mi trabajo. Después de ello yo mismo realicé algunas correcciones y retoqué el libro que te estoy enviando. Vas a conocer el tema del mismo a través del título, el libro te explicará el resto de las cosas que ahora conviene dar a conocer así, sin ningún prólogo. Deseo que me escribas y me cuentes qué te pareció el texto en su totalidad y en cada una de sus partes. Voy a ser muy cuidoso en no hacerlo circular o en publicarlo, según tu crítica se incline hacia uno u otro lado».

9 Traducción: «Acerca de Bruto te voy a escribir todo. Te voy a enviar rápidamente el libro Acerca de la gloria, voy a componer algo como Heraclides, para que quede escondido en tus archivos». Esta misma situación relacionada con la confianza hacia el amigo que no haría circular el envío del poeta, es posible advertirla en otra carta de Cicerón (Att.13.21), en la que 'reta' a su editor por haber hecho público un texto sin que él mismo se lo señalara: dic mihi, placetne tibi primum edere iniussu meo? hoc ne Hermodorus quidem faciebat, is qui Platonis libros solitus est diuulgare (...) Traducción: «Dime ¿te parece bien publicar sin orden mía? Ni siquiera lo hacía Hermodoro, que solía difundir los libros de Platón»
} 
dan cuenta de este ejercicio, ninguna permite pensar en la búsqueda de críticas de 'desconocidos'. Las correcciones que surgían le otorgaban mayor valor al texto para que el mismo asumiera su forma definitiva, tal como lo señala Marcial:

Ruris bibliotheca delicati,
uicinam uidet unde lector urbem,
inter carmina sanctiora si quis
lasciuae fuerit locus Thaliae,
hos nido licet inseras uel imo,
Septem quos tibi misimus libellos
auctoris calamo sui notatos:
haec illis pretium facit litur $(7.17)^{10}$.

Luego de esa instancia de evaluación, era el mismo autor el que volvía 'público' su trabajo. Esto se materializaba a través del envío de copias hechas en su casa a determinados amigos. Una vez que esto sucedía, y sin que mediase el pedido de discreción por parte del autor, el control sobre la propia obra se perdía, dado que el texto podía ser copiado por un amigo de un amigo y así sucesivamente. Cuando el autor, en esa cadena, dejaba de ser quien asumía el gasto de los ejemplares de su obra, perdía esa autoridad primera que le confería la elección de sus lectores y entonces su texto se volvía público (Starr 1987, pp.213-214). Ello también se producía desde el momento en que determinados ejemplares comenzaban a ser copiados para formar parte de las bibliotecas públicas ${ }^{11}$. El texto se volvía 'público' cuando se costeaba ya no con fondos del escritor, sino con dinero del que quería copiarlo. Al mismo tiempo, era frecuente que en esta instancia el autor, para volver público su trabajo, ofreciera una recitatio abierta, tal como lo testimonia Ovidio (Tr.4.10.56-60):

\section{notaque non tarde facta Thalia mea est; carmina cum primum populo iunenilia legi, barba resecta mihi bisue semelue fuit (...). ${ }^{12}$}

Tanto Ovidio como Plinio, al referirse a la situación de la recitatio, hablan de ellos en calidad de autores y, al mismo tiempo, de sus lectores. Las dos situaciones propuestas en ambos textos se diferencian por la enunciación del auditorio. Mientras que en la escena que refiere Plinio el auditorio está conformado por algunos pocos (aliquos, paucos) y son convocados (aduocaui) por el escritor, en la escena relatada por Ovidio el auditorio es mayor y más amplio que el anterior ya que aparece mencio-

\footnotetext{
10 Traducción.: «Biblioteca de una elegante quinta desde donde el lector ve la ciudad vecina, si en medio de los poemas más celebrados existiese lugar para mi lasciva Talía, puedes colocar aún en el último estante los siete libritos que te mandé, corregidos por la mano del propio autor, esto les da valor».

${ }^{11}$ La primera biblioteca pública en Roma fue fundada por Asinio Polión en el año 39 a.C. y se estima que para mediados del siglo IV en Roma existían por lo menos veintiocho.

12 Traducción: «No tardó mi Talía en hacerme conocido; cuando primero leí mis poemas juveniles me había afeitado solo dos o tres veces».
} 
nado como 'el pueblo' (populo) y está ligado a la 'popularidad' temprana del poeta. En este caso se supone que el texto que debió leer Ovidio frente a un público más amplio debió haber sido un texto 'corregido', dado que la lectura frente a desconocidos no buscaba correcciones, sino difusión de la obra. Los lectores, representados en los mismos textos que leen, dan cuenta de un mapa complejo de las relaciones de un determinado momento de la historia de la cultura latina. Esto nos lleva a pensar en las prácticas sociales de lectura y en las distintas funciones, no antagónicas, sino complementarias en muchos casos, en torno a los roles del lector y el escritor que surgen de los mismos textos en los que se dibujan sus roles.

Al analizar distintas escenas de lectura en textos de autores de la Modernidad, Ricardo Piglia (2005, p.33) señala que «la pregunta qué es un lector es también la pregunta sobre cómo le llegan los libros al que lee, cómo se narra la entrada en los textos»». Nosotros volcamos este interrogante sobre las relaciones escritor-lector en la Antigüedad Latina. Los textos con los que trabajamos no solo hablan de los actores involucrados en esta transacción sino que dan cuenta de distintas figuraciones del lector que funcionan como determinantes no solo del ejercicio sino también del proceso de producción escrita. En relación a ello, entendemos que es importante historizar esta cuestión. La pregunta de cuántos individuos podían leer, puntualmente en el período que nos convoca (siglo I a.C. y I d.C aproximadamente), no tiene respuesta cierta. En este sentido, Guglielmo Cavallo, al retomar las palabras de E. Auerbach, señala que el público lector era una minoría, «ni millones, ni siquiera centenares de miles, tal vez no más de algunas decenas de miles en los mejores tiempos» (Cavallo 2011, p.104). La cuantificación, en estos casos, se vuelve una variable imposible. Resulta más interesante, entonces, preguntarse quiénes y cómo leían el material sobre el que nos proponemos trabajar. Si bien durante mucho tiempo la lectura como tal ha aparecido como un bien propio de los más ricos, numerosos testimonios de escenas de lecturas en los frescos, en los mosaicos y en los relieves de la época permiten afirmar que se trataba de una práctica más extendida y más popular de lo que en muchos casos se creyó. Quizá la simplificación del concepto 'lectura' haya sido el motivo que materializó dicha práctica como un privilegio de los más cultos. El concepto de lectura de la Antigüedad excede tanto la capacidad de descifrar signos lingüísticos que probablemente se haya construido el error de asignárselo a quienes pudieran adquirir todas estas destrezas que mencionamos antes. En efecto, durante el período que nos ocupa la difusión de la alfabetización llegó tanto a los más modestos como a los que poseían una educación media. Se trataba, en muchos casos, de distintos modos de leer, pero de leer al fin. Esto produjo un incremento en el público lector, de modo tal que este no siempre resultó reconocible ni identificable, lectores despreocupados por los elementos técnicos del libro que leían «por la uoluptas y no por la utilitas» (Cavallo 1998, pp.103-104). Al mismo tiempo de la existencia de este público lector, existía el mundo de los escritores, que sí era una cuestión de elite que involucraba a una parte de la población muy reducida que trazaba relaciones endogámicas en torno a sus trabajos y a sus primeros destinatarios.

En la carta 1.8.2- 4, dedicada a Pompeyo Saturnino, Plinio le habla a su lector y le dice cómo debe leer: 
Petiturus sum enim ut rursus uaces sermoni quem apud municipes meos habui bibliothecam dedicaturus. Memini quidem te iam quaedam adnotasse, sed generaliter; ideo nunc rogo ut non tantum uniuersitati eius attendas, uerum etiam particulas qua soles lima persequaris. Erit enim et post emendationem liberum nobis uel publicare uel continere. 4 Quin immo fortasse hanc ipsam cunctationem nostram in alterutram sententiam emendationis ratio deducet, quae aut indignum editione dum saepius retractat inueniet, aut dignum dum id ipsum experitur efficiet ${ }^{13}$.

Plinio, al incluir a su lector elegido y convertirlo en especialista, le dice no solo cómo debe leer (particulas, por partes pequeñas), sino que le señala también que debe leer separado de la realidad, pues debe leer en su tiempo libre (vaces), alejado de las actividades cotidianas, pues no lo hizo en la presentación de la biblioteca como los individuos que estaban presentes en ese momento, sino que debe instalarse en el espacio preferencial del crítico, de la clase de crítico que, como lo señala en el discurso, lee palabra por palabra detenidamente. Al sustraer el texto de la performance que suponía la lectura en público, el autor le quita al lector todos los elementos propios de tal situación (el deslizamiento del rollo entre sus manos, el tono de voz elegido, los silencios, el sonido que rodea la situación) y deja solo el texto. Entonces, la lectura del lector crítico aparece sugerida por el escritor que no solo 'lo obliga' a una lectura individual, sino que también, según se advierte en la carta 1.8., le dice cómo leer: ya no el texto como un todo porque esa fue una lectura previa (te iam quaedam adnotasse, sed generaliter) sino una lectura más detenida. Le pide que se detenga en lo más pequeño. De esta manera, el escritor condiciona la lectura del crítico para obtener un texto corregido, acotado, pulido por las correcciones del lector. Así, en el trayecto de las correcciones, el escritor aparece como 'el que mira leer al que lee', que es el crítico, que lee porque otro se lo pide, que lee contra otro lector (Piglia 2005, p.35). En este marco, y tal como lo señala Plinio, las críticas podían ser entendidas como una censura o como una habilitación. La idea de no publicar protegía al escritor contra una mala crítica que no era vergonzante si provenía de un par pero cuyo valor se volvía radicalmente negativo si era proferida por un desconocido.

Así, la escritura ligada a la corrección aparece como una metáfora de la relación 'con los otros' que pertenecen a un reducido círculo intelectual. Este primer lector, que lee buscando el error, que corrige para que otros no corrijan, participa de una etapa de la circulación del texto. El escritor, bajo condiciones que él mismo propone, somete su obra a la corrección de algunos de sus pares e inicia de esa manera el circuito de publicación de su texto.

\footnotetext{
13 Traducción: «Voy a pedirte que en tu tiempo libre mires de nuevo el discurso que pronuncié frente a los ciudadanos cuando iba a inaugurar la biblioteca. Recuerdo que ya hiciste algunas sugerencias generales, pero esta vez te pido que observes no solo el texto como un todo, sino que te detengas en cada una de sus pequeñas partes con el cuidado que acostumbras a tener cuando corriges. Así, después de esta corrección podré publicar o guardar el libro. Y aún más, esta decisión dependerá también de lo publicable o no publicable que resulte el libro según las correcciones que deba hacer».
} 


\section{REFERENCIAS BIBLIOGRÁFICAS}

Cavallo, G. (2011), «Entre el volumen y el codex», en Cavallo G. - Chartier R., Historia de la lectura en el mundo occidental, Madrid, Taurus, pp.99-128.

Cavallo G. - Chartier R. (2011), «Introducción», en Cavallo G. - Chartier R., Historia de la lectura en el mundo occidental, Madrid, Taurus, pp.25-65.

HABINEK, T. (1998), The politics of latin literature. Writing, identity and empire in ancient Rome, Princeton, New Jersey.

Harris, W. V. (1983), «Literary and Epigraphy», Zeitschrift für Papyrologie und Epigraphik 52, pp.87-111.

KenNeY, E. J. (1989), «Libros y lectores en el mundo de la antigua Roma», en Historia de la literatura clásica, Madrid, Gredos, T. II, pp.15-47.

Kenyon, F. G. (1932), Books and Readers in Ancient Greece and Rome, Chicago, Ares Publishers.

Marrou, H. I. (1965), Historia de la educación en la Antigüedad, Buenos Aires, Editorial Universitaria de Buenos Aires.

PÉRez CoRTÉs, S. P. (2000), «Leer, oír, cantar. El lector en la Antigüedad», Alteridades 20.1, pp.117-127.

Piglia, Ricardo (2005), El último lector, Barcelona, Anagrama.

Proust, M. (2003), Sobre la lectura, Buenos Aires, Libros del Zorzal.

STARR, R. (1987), «The circulation of literary texts in the roman world», Classical Quaterly 37.1, pp.213- 223.

VAN SIECKLE, J. (1980), «The book- roll and some conventions of the poetic book», Arethusa 13.1, pp.5-42. 